\title{
1. A socio-evolutionary approach to sexual harassment
}

The genesis of this book was simple: a long-time collaborator and I had edited a volume called Leadership and Sexuality: Power, Principles and Processes (Beggan \& Allison, 2018). The book combined his academic interest in leadership and heroism and my research interest in human sexuality. One topic was noticeably missing from the book: anything about Harvey Weinstein or the \#MeToo movement, or the host of other men who were the subject of sexual harassment scandals in the aftermath of the Harvey Weinstein accusations. The reason for this omission was painfully obvious: the book was written and set into print before the news of the scandals hit the papers. I initially lamented missing the boat on these topics. Then I realized rather than just regret what had not happened, I should get on the next boat. I should start a new project, a book that examined the Harvey Weinstein et al. scandals in the \#MeToo era.

The purpose of this book is to put forward an interactionist perspective to sexual harassment that integrates utility theory, evolutionary theory, and sexual scripting theory. I present a sexual approach model that uses utility theory to describe a way to think about how men approach women for sex. Because the focus of the model is on explaining men's sexual harassment of women, I intentionally use gendered pronouns that assume the harasser is male and the target is female. I recognize that other patterns of gender harassment are possible (such as men harassing men or women harassing men); however, the most frequent takes the form of men harassing women. As such, I feel justified in presenting my arguments using what otherwise might be criticized as possessing a heteronormative bias.

Utility theory has its origins in economics and rational actor approaches to understanding how people deal with risk (Fishburn, 1970). It suggests that the value of an option is a function of the payoff the option affords and the likelihood of actually obtaining that payoff. Men are more likely to approach the more positively they evaluate the opportunity to have sex with the target person. They are also more likely to approach to the extent that they expect to be successful. Further, I suggest that men do not merely assess likelihood. They also take steps to influence it. In other words, the approach model suggests that men persuade women to have sex with them. The influence tactics men use can be understood in terms of preferred mating strategies that have 
evolved as a result of biological differences in the way that men and women reproduce (Buss \& Schmitt, 1993). If an influence attempt is sufficiently unwanted it can be viewed as sexual harassment. I use sexual scripting theory, which can be situated within symbolic interactionism and highlights the way social reality is constructed by individuals and culture, to consider what makes a woman encode an approach as harassment (Gagnon \& Simon, 1973). Sexual scripts refer to expectations people have about how to behave in sexual situations. Differences between men's and women's sexual scripts can help account for why women encode men's behavior as harassment.

This book is called Sexual Harassment, the Abuse of Power and the Crisis of Leadership. An initial reading of the title suggests the book would make the case that sexual harassment represents a crisis of leadership because those committing sexual harassment are abusing their power as leaders. I suggest that the allegations of sexual misconduct against Donald Trump, and perhaps more importantly his defiant response to those allegations, were a turning point in the fight against sexual harassment. My suggestion is that the events around Donald Trump triggered a collective rage that was unleashed against Harvey Weinstein and many others as an unprecedented level of political and social activism (Weldon, 2018). A recent target of this new order was Brett Kavanaugh, the nominee for the Supreme Court, whose confirmation was challenged but ultimately not stopped by credible allegations of sexual assault by Christine Blasey Ford. The results of the 2018 midterm election, most conspicuously the now Democrat majority in the House of Representatives, can be viewed as a challenge by women to Trump's attitudes (North, 2018a).

\section{THE POLARIZED SEXUAL HARASSMENT DEBATE}

As noted by Proulx, Pepper, and Shulten (2018), "The Times uses the terms 'sexual harassment' and 'sexual misconduct' to refer to a range of behaviors that are sexual in nature and nonconsensual. The term 'sexual assault' usually signifies a felony sexual offense, like rape." Although there are important differences between terms like sexual harassment, sexual misconduct, and sexual assault, they have lost some of their distinctiveness as society's views have polarized to the extent that all social interaction with a sexual element is now potentially viewed by some people under certain circumstances as sexual harassment, unless an explicit understanding of prior consent is obtained (Sepulveres, 2017).

An example of this polarization is the reexamination every Christmas of the song "Baby, It's Cold Outside" as either a cute and romantic call-and-response tune or as a dramatization of date rape (Crockett, 2016). The song is a duet between a man and a woman where they debate whether the woman should 
go home or stay the night. The thought of leaving is uninviting because of the chill temperatures, but there is also the worry over what the neighbors or their relatives might think. Their conversation can be read as coercive in a manner that could lead to an unwanted sexual advance or as merely a caution that the bad weather should encourage her to stay.

While I agree that it is for the overall good of society to bring forward cases of unwanted sexual behavior, hypersensitivity can lead to a breakdown of trust between the sexes and a diminishment of true cases of harassment or assault, which then get watered down in a pool of less-justified accusations. My intention with this book is to try to talk in an honest and critical way about actions that can be interpreted as sexual harassment. I can imagine some people taking what I am saying out of context to suggest that I support (or am not sufficiently against) sexual harassment. Instead, a more correct interpretation of my argument is that certain aspects of what is labeled sexual harassment can be viewed as an outgrowth of what can be labeled "normal" sexual relations between men and women, as derived from an evolutionary perspective. Although evolutionary theory can be a contentious lens with which to interpret the phenomenon of sexual harassment, my defense is based on the belief that to change policies toward sexual harassment it is necessary to be honest about factors that fuel sexual harassment, including those derived from evolutionary pressures.

\section{POWER AND SEXUAL HARASSMENT}

One of the strongest messages of the \#MeToo movement is that sexual harassment is about power not about sex. From the power perspective, particular men exercise power over specific women, but that use of power was also manifest at a broader, institutional level where men as a collective - variously described as masculinity, patriarchy, or hegemonic masculinity - exercised power over society as a whole, including the women who were part of that society.

Welsh (1999) describes a number of models of sexual harassment, such as the socio-cultural model that frames sexual harassment in terms of power and status differences between men and women, which are legitimized by cultural forces. A different view of power is contained in models that focus on the way organizational structures can perpetuate sexual harassment. Another approach - sex ratios - focuses on power in terms of numerical advantage and focuses on the relative numbers of men and women in an organization (Gutek \& Morasch, 1982). From a ratios perspective, sexual harassment results from sex role spillover, where a numerical imbalance draws attention to the traditional roles of men and women, especially related to the pursuit of sex, and encourages men to focus on women as sexual beings. Women in male-dominated professions are seen as deviants and perceived in terms of their gender role. What is frustrating for women is that when they operate in female-dominated 
professions, expectations about the work role align with gender expectations, leading perceivers to treat them in a more stereotypic fashion.

The sex role spillover model would suggest that a balanced ratio is best for reducing sexual harassment such that occupations are less sex-typed. On the other hand, from a purely mathematical perspective, a more balanced sex ratio would increase the likelihood of sexual harassment. For example, in a ten-person firm, if there are ten men and no women, the number of (crosssex) harassment incidents would be zero. With nine men and one woman, the number would be nine. With the most integrated possibility (five men and five women), 25 incidents would be possible. The general formula would be the product of the number of men and number of women, assuming that only men harass, and men only harass women, and the likelihood of an incident is independent of other incidents. From this perspective, the more contact there is between men and women, the more opportunities there are for harassment to occur.

In modern society, the acquisition of power almost always means the same thing as the acquisition of money or status cues such as a favorable reputation. One way to achieve both those goals simultaneously is through becoming a leader. Being a leader also carries with it certain responsibilities for the well-being of constituents, that is, leadership is also associated with collective concerns. Another way to gain money and status is to be a high-value performer, i.e., a superstar. Being a superstar is a much more individualistic, own gain-oriented goal. A superstar has many of the perks of being a leader but fewer of the responsibilities. As such, it is possible that one predictor of engaging in sexual harassment would be to be a high-value employee. In keeping with this argument, Dowd (2017) reported that when Susan Fowler, the engineer who exposed the misogynistic, sexual harassment culture at the ridesharing company Uber, complained that her manager was sending her sexually oriented texts, she was told that he was a "high performer," and apparently immune from consequences. As noted by McGregor (2018), "The \#MeToo movement has provided countless examples of situations where the arms race to recruit or retain star talent has been linked with the toleration of inappropriate behavior or at least raised questions about how companies responded when confronted with past alleged actions of top executives".

\section{THE POLITICAL POWER OF SEXUAL HARASSMENT}

There is another way to think about the use of power in the context of sexual harassment. It is not the way that power is most often thought about with regard to sexual politics, which tends to be geared toward understanding-or combating - male power (termed patriarchy), but rather in terms of the power 
that exists to shape the social discourse about what exactly constitutes sexual harassment. A key idea of this book is that power-defined as social, political, and legal influence- has been used to shape what behaviors should be included in the category of sexual harassment. In the latter part of this book, I will argue that our society's consensual meaning of sexual harassment has shifted toward a broader definition, which, in turn, has produced a more restrictive view of what is acceptable social behavior, especially in the workplace and university environment. The net result of this power struggle has been to restrict the free expression of sexual or romantic interest in a social domain, an outcome which contradicts what would be expected from a more liberal point of view on sexual expression.

Although certain men in authority were the most direct and obvious examples of the abuse of power, there were other ways in which leadership, power, and authority were involved in the phenomenon of sexual harassment. This new form of the abuse of power was to use the threat of the dangers of sexual harassment to mount an attack on sexuality itself. The goal was not just to eliminate sexual harassment from the workplace; it was to eliminate sex from the workplace, even sexual expression that would not have constituted a legal definition of sexual harassment.

The person who was probably most influential in using the concept of sexual harassment as a tool to undermine sexuality was Catharine MacKinnon. In her 1979 book Sexual Harassment of Working Women, she argued that sexual harassment was a form of sex-based discrimination protected against under Title VII of the Civil Rights Act of 1964. Her goal was to use the threat of sexual discrimination lawsuits as the basis for the removal of sexuality in the workplace. She was one of the leading forces in radical feminism, and her position epitomized the idea that the appropriate lens to understand any kind of sexual behavior between men and women was as an expression of power, specifically, men's power (as individuals and as members of patriarchy) over women (as individuals and collectively as an oppressed class).

The decision to frame sex-based discrimination in terms of sexual harassment produced three unfortunate consequences. The first was that the drive to stamp out sexual harassment - as the sole means of combating sex-based discrimination - expanded the definition of sexual harassment to such a degree that it also targeted behavior that did not fall within the scope of sex-based discrimination and in some cases failed to meet the definition of what could genuinely be called sexual harassment. Another unfortunate consequence was that preventing sexual harassment became a threat to individuals' rights to free expression, even the rights of consenting adults to engage in consenting behavior outside the workplace. The third result was to exclude from the popular conversation instances of workplace discrimination that did not involve a sexual harassment element. In other words, by creating and focusing on a false 
equivalence between sexual harassment and sex-based discrimination, cases of sex-based discrimination that did not conform to the parameters of sexual harassment were left by the wayside.

This radical wing of the feminist movement teamed up with an unexpected ally: big business. It was an unlikely and paradoxical alliance because of the inherent conflict between the central tenets of their perspectives. Business organizations were classic examples of the operation of patriarchy. It was not hard to make the case that they were dominated by men, put a premium on what could be readily construed as masculine values (such as a strict hierarchical structure) and were organized and run in ways that benefitted men and continued a systemic oppression of the interests of women. Simultaneously, however, organizational approaches saw the infusion of emotionality as a potential distraction from the profit-making motive; romantic and sexual emotionality were the biggest threats of all. Companies wanted to restrict romantic entanglements as a means of improving efficiency. As the threat of lawsuits related to sexual harassment grew, this also legitimized corporate efforts to ban sex from the workplace. As a result, both the feminist movement and management philosophies could be united in a fight against sexual expression.

The phenomenon that radical feminists would team up with an unlikely ally also took place with regard to attacks on pornography. In her book, Toward a Feminist Theory of the State, MacKinnon (1989) argued that pornography could be conceptualized as a form of discrimination against and violence toward women. Extreme anti-pornography feminists joined forces with conservative Christians to protest against pornography as well as prostitution (Michaelson, 2016).

A third group who abused their power were human resource professionals, who helped define the boundaries of what would be defined as sexual harassment. They translated legal concepts related to Title VII and Title IX from the court to the boardroom. In the process, they probably erred on the side of expanding the definition, out of a genuine desire to be cautious but also perhaps out of a self-serving desire to enhance their own importance. Even if this broadening of terms was well intended, it had the effect of putting more limitations on the expression of sexuality in the workplace. Human resource managers developed training methods and investigative and punitive procedures to deal with violations of the sexual harassment regulations they helped put into place. They tended to see sexual harassment as a bigger and bigger threat in order to advance their own agendas and consolidate their own power, as moral entrepreneurs tend to do (Goode \& Ben-Yehuda, 1994).

As the threat of sexual harassment grew, or was made to appear more ominous, more and more resources were expended to prevent and avenge it, regardless of whether those expenses could be justified in terms of the demonstrable value of the services being purchased (Kalev, Dobbin, \& Kelly, 2006). 
Training programs to guard against sexual harassment are widespread in the American workplace (Perry, Kulik, Bustamante, \& Golom, 2010) and cost an estimated \$10 billion a year in the United States alone (Goldberg, 2011).

One cynical but quite plausible explanation for the lack of validation of sexual harassment training is that programs are less about actually imparting useful knowledge than they are about reducing legal liability for companies (Bisom-Rapp, 2001). The concerns that these programs addressed were less about the women who were the potential victims of sexual harassment and more about the companies that employed both the women and men. Although defending women who were sexually harassed was certainly a valuable goal, in the process of protecting the companies for which they worked, the rights of others, such as the accused, were being violated, and more and more types of behaviors were being classified as sexual harassment.

\section{THE ROLE OF SEX IN SEXUAL HARASSMENT}

At first, sexual harassment was viewed as an inappropriate means by which men attempted to achieve sexual gratification by taking advantage of women with lesser status, either by virtue of their relative positions within an organization or in terms of systemic forces that operated to offer more power to men relative to women.

In the next wave of thinking, the motive for sex was subordinated to a lesser position. It became popular to conceptualize sexual harassment as less about sex and more about the power differential between men and women in the workplace (Akerlof \& Kranton, 2000; Berdahl, 2007a; Schultz, 1998; Welsh, 1999). Sexual harassment was seen as a means by which men oppressed women. The reasons for the oppression could vary from a way to systematically subordinate women in order to preserve men's status to one man's efforts to maintain a positive sense of self and power in an environment where women's advances made his dominance less certain. Berdahl (2007a, p. 641) suggested "... the primary motive underlying all harassment is the desire to protect one's social status when it seems threatened" and "... sexual harassers derogate others based on sex to protect or enhance their own sex-based social status, and are motivated and able to do so by a social context that pervasively and fundamentally stratifies social status by sex."

By conceptualizing sexual harassment as motivated by either the use of force to achieve sexual gratification or the use of sex to assert dominance over women, it is possible to miss where the overlap of the two motivations occurs. As a novel approach, I suggest that both sex and power motives operate but instead of asserting that men use sex as a means of controlling women, or that men control women to obtain sex, by incorporating ideas from evolutionary psychology, I explain sexual harassment as related to the normal process by 
which men use their accrued power to attract women for sexual opportunities, not as a means of denigrating the target, and certainly not in a way that is intended to make the target feel bad. In fact, I suggest that the harasser's intention is to make the target feel good as the recipient of sexual attention.

The sexual harassment problem that men have is a disconnection between their beliefs about their influence efforts and the actual effects of their efforts. I assert that this disconnection is more profound because modern cases of approach occur in a workplace context where such behavior is seen as inappropriate. Further, technological innovation and economies of scale have made it possible for men to achieve a concentration of power that is unlike what existed in ancient times and makes it more likely that men will engage in power displays that women find unpleasant rather than alluring.

According to my perspective, sexual harassment-at least some forms of it - is about just what it appears to be about, which is sex. The acquisition and use of power is the means by which men go about obtaining sex (Browne, 2006). In this case, power is the means to an end. And the end in this case is sexual gratification. As noted by Lewis (2000, p. 758), "Power is obviously a very important aspect of sexual harassment because it gives some men the ability to gain sexual access, but it is not the reason men hope to gain access."

The basic tenet of this book - that at least some examples of sexual harassment reflect evolutionary pressures that have been selected for over the span of hundreds of thousands of years - is almost certain to upset sociologists and feminists who have an anathema toward biological explanations, which they term essentialist. A major component of the dislike for evolutionary approaches to social behavior is the assumption that biological (which can be framed as evolutionary, neurological, or biochemical) explanations serve as a justification for sexism as well as an explanation of sex differences. Oddly, even though sociology and feminism - to name just two disciplines - are not that different from psychology, many psychologists - who describe themselves as evolutionary psychologists - seem much more favorably disposed toward biological explanations for social behavior based on the selection of traits that operate through natural selection and sexual selection.

Another source of dislike stems from an unwarranted assumption that biological explanations mean that social change is impossible. Just because sexual harassment can be explained in terms of a natural evolutionary process does not mean we as a society - and women in particular - cannot stop it. But I am asserting that allowing an ideological blindfold to interfere with understanding a phenomenon will definitely impede the process of persuading, encouraging, or even forcing men to change their ways.

It is widely accepted that many sexual harassment training programs are ineffective, designed to protect the organization from legal liability rather than to protect employees from being targeted for sexual harassment (Miller, 2017). 
Part of the reason they do not work is because they are not targeting what they need to target. A goal of this book is to help improve the effectiveness of these training programs by better identifying what is causing problems in the first place. Evolutionary theory is the means to a better process of identification.

\section{WHAT TYPES OF SEXUAL HARASSMENT DO I MEAN?}

Researchers have classified sexual misconduct into different categories and offered numerous explanations for why it occurs. Sexual harassment can be thought about in terms of three distinct types: gender harassment, sexual coercion, and unwanted sexual attention (Page \& Pina, 2015). Gender harassment involves creating an intimidating hostile environment, such as by telling sexist jokes, where the goal of the harassment is to insult or degrade someone rather than to display sexual interest (Berdahl, 2007b). There is evidence that a large percentage of sex-related harassment is more about gender rather than sexual behavior (Berdahl \& Raver, 2011; Leskinen, Cortina, \& Kabat, 2011). Sexual coercion refers to using power as a means to gain sexual access to someone. The degree of coercion can range from relatively subtle, such as pestering or nagging, to an intermediate level, such as threatening someone's employment, to severe, such as using physical force. One way to understand sexual harassment is in terms of whether the harassment is physically invasive or can be seen as a gateway to other, more extreme forms of harassment (Knapp, Pierce, \& DuBois, 2015).

With the third type, unwanted sexual attention, the harasser displays sexual interest in a target using behaviors that are offensive, not desired, and unreciprocated (Pina \& Gannon, 2012). Despite the importance of gender harassment - as opposed to sexual harassment - it is clear that the problem of the inappropriate expression of sexuality is an important issue that needs to be better understood in the hopes of developing more effective means of limiting it.

Feminist critiques of sexual harassment have suggested that we need to take the subjective opinion of the woman who is the target of harassment into account. It is not sufficient to make a defense based on either the intentions of the male harasser - who might claim he did not mean anything harmful — or some assessment of objective facts, i.e., what a reasonable man-or even what a reasonable woman - might think. What matters, from this subjectivity perspective, is how the woman was made to feel.

Although politically incorrect to make this assertion, I think it is important to also consider the man's state of mind with regard to harassment. Did the man intend to make the woman feel uncomfortable? If so, the behavior in question serves as form of gender-based harm, which-although an important 
topic-I find to be less interesting from a psychological perspective. It is interesting to try to understand why some people will harm others, why there is aggression in the first place, but there already exists a tremendous literature on criminal behavior. There are already laws on the books that deal with physical and psychological harm that people commit against others, in both sexual and nonsexual domains. As such, gender harassment and sexual coercion that involves force are topics outside the scope of this book.

One example of sexual behaviors outside of my range of consideration is the crimes of Bill Cosby, which we already have laws to deal with, namely sexual assault and rape (Kim, Littlefield, \& Etehad, 2017). Harvey Weinstein has engaged in behaviors that fall into the category of criminal behavior (Winton \& Queally, 2018). Some actresses such as Salma Hayek, Rose McGowan, and Gwyneth Paltrow have accused him of rape (BBC News, 2018). According to the accuser Lucia Evans, he was "simultaneously flattering me and demeaning me and making me feel bad about myself." According to her account, he exposed his penis and pulled her head down toward it. She explained why she acquiesced to his desires with the comment, "I just sort of gave up. That's the most horrible part of it, and that's why he's been able to do this for so long to so many women: People give up, and then they feel like it's their fault."

Instead of behavior that meets a clear criminal standard, I am most interested in understanding behaviors where the harasser might operate under the assumption that the proposed sexual transaction is desired by the target whereas in reality the target of harassment is uncomfortable by the interaction. My goal is to use evolutionary psychology as the conceptual basis to examine factors related to leadership and sexuality that encourage men and women to view the same social transaction differently. Finally, I intend to examine how competing approaches - situated in feminism, organizational studies, and the law - can be construed as representing a power struggle regarding when and how certain behaviors should be conceptualized as sexual harassment and how one outcome of this struggle has been to create a movement that can be used to distance people from their own sexuality and, in the process, reify a traditional view of human sexuality that both creates and serves as the justification for this alienation. 